Ciência eNatura, Santa Maria, v. 37 Part 1 2015, p. 12-14

ISSN impressa: 0100-8307 ISSN on-line: 2179-460X

\title{
ciênciaenatura
}

\section{Computational study adsorption of mercaptopurine in generation G3 and G5 PAMAM dendrimers}

Frydon Ashrafi, Tahereh Mahbobi ", Ashraf Sadat Ghasemi

Department of Chemistry, Payame Noor University (PNU), P.O. Box,19395-3697, Tehran, Iran

\begin{abstract}
Due to its unique properties of dendrimers as well as with high-level groups, a special ability to carry drugs. In this study compared the interaction between the two generations of poly (amidoamine) PAMAM (G3and G5) dendrimers and the drug 6-mercaptopurine (6-MP) and the drug entrapment within the structure of dendrimers the electrostatic and covalent complexation of drugs to the dendrimer surface have been studied. The use of drug-dendrimer complex enhanced drug solubility and bioavailability of the drug.
\end{abstract}

Keywords: PAMAM, dendrimer, 6-mercaptopurine, bioavailability. 


\section{Introduction}

$\mathrm{E}$ dendrimers differ from many classical polymers, such as linear and branched polymers, in that they are well-defined, with a high degree of molecular uniformity and monodispersity, as well as a highly functional surface [1-4]. In general, low generation dendrimers have an open structure, but as the generation increases the structure becomes more globular and dense. However the number of guest molecules incorporated into a dendrimer may be dependent to a limited extent on the architecture of a dendrimer, the loading capacity may be dramatically increased by the formation of a complex with the large number of groups on the dendrimer surface.The number of surface groups available for drug interactions doubles with each increasing generation of dendrimer. It should be borne in mind that not all of the surface groups in a dendrimer may be available for interaction, either because of steric hindrance or backfolding of chains into the dendrimer[5]. G5 PAMAM dendrimers has 128 branches and a spherical shape. Backfolding of chains into the dendrimer, are causing spherical shape. It is a cationic dendrimers. The presence of large numbers of ionizable groups on the surface of PAMAM dendrimers provides an interesting opportunity for electrostatic attachment of numerous ionizable drugs, providing the resultant complex retains sufficient water solubility [5].

Mercaptopurine (6MP), a drug used to treat leukemia. Dendrimers can be a good carrier for this drug. In this study, absorption of the drug in the presence of three different generations dendrimer is done. The structure of dendrimers G3 and G5 by using DFT and MM, is optimized. The optimization was performed in the presence of $6 \mathrm{MP}$ and energy of three dendrimers were compared.

The table below shows the number of surface groups and molecular weights of the two dendrimers was shown

\section{Method}

All the calculations in the present study have been performed using the development version of the Gaussian program, the method and basis set to use for in computational study was ONIOM 2 layers B3LYP/3-21G level[3,4].

\section{Figures}

The purpose of this research is better absorption of drugs by drug delivery. After taking the drug near the terminal surface functional groups and optimization, summary structures in Fig 1- 3 have been shown.

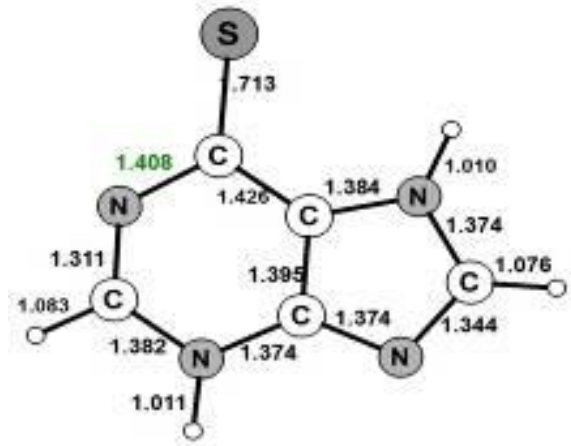

Figur 1: Schematic representation of general structure of optimazed Mercaptopurine (6MP).

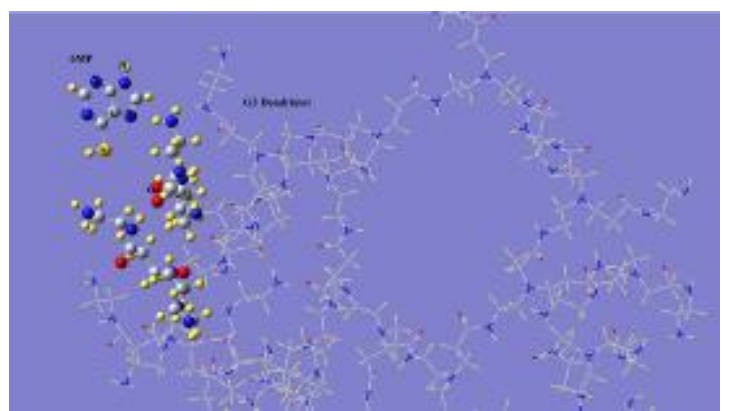

Figur 2: G3PAMAM dendrimer and 6MP 


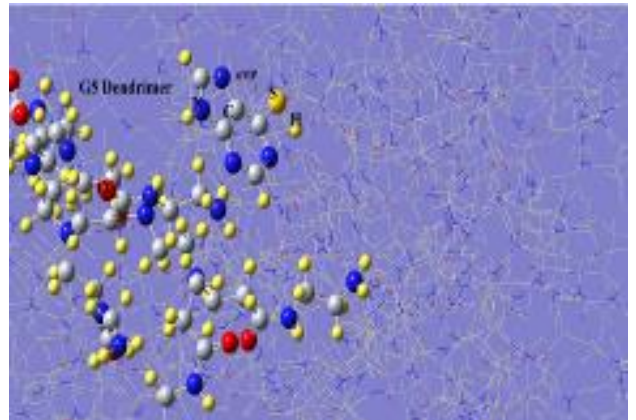

Figur3: G5 PAMAM dendrimer and 6MP

\section{4 tables}

Dendrimers Dendritic architecture holds immense potential overthe other carrier systems, particularly in the field of drug delivery, because Figur3: Schematic representation of general structure of optimazed dendrimers (G5). of their unique properties. As comparedto traditional linear polymers, dendrimers exhibit signifi-cantly improved physical and chemical properties.

Table. 1. Theoretical details of different generation of PAMAM dendrimers.

\begin{tabular}{|c|c|l|l|}
\hline $\begin{array}{l}\text { Genera } \\
\text { tion }\end{array}$ & $\begin{array}{l}\text { Surface } \\
\text { groups }\end{array}$ & Molecular formula & $\begin{array}{l}\text { Molecular } \\
\text { weight }\end{array}$ \\
\hline 3 & 32 & $\mathrm{C}_{302} \mathrm{H}_{672} \mathrm{~N}_{122} \mathrm{O}_{60}$ & $6,973.348$ \\
5 & 128 & $\mathrm{C}_{1262} \mathrm{H}_{2534} \mathrm{~N}_{506} \mathrm{O}_{252}$ & $28,868.077$ \\
\hline
\end{tabular}

Summary of The comparison energy of Ead, Еномо, Elumo and Dipole moment PAMAM G3 and G5 dendrimers complexation with 6-MP shown in Table 2.

Table. 2. Comparison Ead, Еномо, Elumo and Dipole moment between complex dendrimers and drug

\begin{tabular}{|c|c|c|c|c|c|}
\hline Dendrimers and drug & $\mathrm{E}_{\mathrm{ad}}(\mathbf{k j} / \mathrm{mol})$ & E(HOMO) & E(LUMO) & $\begin{array}{l}\text { Bond } \\
\text { gap(Hartree) }\end{array}$ & $\begin{array}{l}\text { Dipole } \\
\text { moment }\end{array}$ \\
\hline PAMAM(G5) & -106736.468 & -0.00228 & 0.00370 & 0.00142 & 2.794 \\
\hline PAMAM (G3) & -19075.096 & -0.02020 & 0.01523 & 0.00497 & 1.985 \\
\hline
\end{tabular}

The purpose of this research is better absorption of drugs by drug delivery.

The adsorption energy (Ead) between drug and the dendrimer was calculated according to Eq.

$$
\mathrm{E}_{\mathrm{ad}}=[\text { EpAMAM }+ \text { drug }]-\left[(\text { EpAMAM })+\left(E_{\text {drug }}\right)\right]
$$

\section{Conclusion}

We have calculated the geometrical structure, effective stability using density functional theory. Our results show G3 and G5 PAMAM dendrimers are a better drug delivery for 6-MP and more terminal amide groups have more effective in stability of dendrimers.

\section{References}

Frisch, M. J. et al., (2002). Gaussian 98 A.11.3, Gaussian Inc., Pittsburg, USA.
Morokuma K. and Frisch, M. J. (1999). A New ONIOM Implementation in Gaussian 98. Part 1.

The Calculation of Energies, Gradients and Vibrational Frequencies and Electric Field Derivatives, J. Mol. Struct. (Theochem) 462, 1.

Tomalia, D.A., Baker, H., Dewald, J., Hall, M., Kallos, Martin, G., S., Roeck, J., Ryder, J., Smith, P. (1985) A new class of polymers: starburstdendritic macromolecules, Polym. J. (Tokyo) 17117- 132.

Naylor, A.M., Goddard III, W.A., Kiefer, G.E., Tomalia, D.A. (1989) Starburst dendrimers: 5. Molecular shape control, J. Am. Chem. Soc. 111, 2339-2341.

Tomalia, D.A., Naylor, A.M., Goddard III, W.A., (1990) Starburst dendrimers: molecularlevel control of size, shape, surface chemistry, topology and flexibility in the conversion of atoms to macroscopic materials, Angew. Chem., Int. Ed. Engl. 29, 138- 175.

Matthews, O. A., Shipway, A.N. Stoddart, J. F. (1998) Dendrimersbranching out from curiosities into new technologies, Prog. Poly. Sci. 23, 1- 56 .

Emanuele, A. D., Attwood, D., (2005) Dendrimer-drug interactionsB, Advanced Drug Delivery Rev. 57, 2147- 2162. 